\title{
VIRTUDE, AGÊNCIA E RESPONSABILIDADE: UMA PERSPECTIVA EPISTEMOLÓGICA
}

\author{
Kátia M. Etcheverry ${ }^{1}$ \\ Pontifícia Universidade Católica do Rio Grande do Sul (PUCRS) \\ (D) http://orcid.org/0000-0002-0093-1089
}

\begin{abstract}
RESUMO:
O foco de interesse neste artigo se coloca na relevância da noção de agência para análises de conhecimento em termos de virtude epistêmica, destacando a estratégia assumida por epistemólogos da virtude na defesa da tese de que podemos ser agentes responsáveis pelo que constitui nossa vida epistêmica, apesar de nossas crenças serem estados involuntários. Enquanto L. Zagzebski (2001), invocando casos epistêmicos do tipo Frankfurt, alega que considerar agência epistêmica como condição necessária para o conhecimento permite oferecer uma análise que escapa à famosa objeção de Gettier, E. Sosa (2015) refina sua teoria, oferecendo nova argumentação em favor da ideia de que há uma esfera epistêmica na qual podemos ser agentes e responsáveis pela aquisição de crenças verdadeiras devido à importância de nosso caráter cognitivo para a atribuição de conhecimento. Meu objetivo ao expor e comparar as posições de Zagzebski e de Sosa é colocar em relevo aspectos do atual estado da arte em epistemologia da virtude que favorecem explicações de conhecimento em termos de crédito.
\end{abstract}

PALAVRAS-CHAVE: Agência Epistêmica; Responsabilidade Epistêmica; Casos Frankfurt Epistêmicos; Teoria do Crédito.

\section{VIRTUE, AGENCY AND RESPONSIBILITY: AN EPISTEMOLOGICAL PERSPECTIVE}

\begin{abstract}
:
This article focus on the relevance of epistemic agency to analyze knowledge in terms of epistemic virtue, highlighting the strategy adopted by virtue epistemologists to argue for the thesis that we can be epistemic agents, responsible for our epistemic lives, even if our beliefs are involuntary states. While L. Zagzebski (2001), by way of epistemic

\footnotetext{
${ }^{1}$ Doutora em filosofia e professora em estágio pós-doutoral (PNPD/CAPES) no Programa de Pós-Graduação em Filosofia da Pontifícia Universidade Católica do Rio Grande do Sul
} (PUCRS), Rio Grande do Sul - Brasil. E-mail: katia.etcheverry@acad.pucrs.br.
\end{abstract}


Frankfurt-style cases, claims that considering epistemic agency as a necessary condition for knowledge allows to offer an analysis that escapes the famous Gettier objection, E. Sosa (2015) refines his theory, offering new argumentation for the idea that there is an epistemic domain where there can be agency and we can be responsible for our true beliefs because of the significance of our cognitive character in knowledge acquisition. My aim in presenting and comparing Zagzebski's and Sosa's proposals is to emphasize some aspects in the current state of the art in virtue epistemology that favor credit accounts of knowledge.

KEYWORDS: Epistemic Agency; Epistemic Responsibility; Epistemic Frankfurt cases; Credit Theory of Knowledge.

\section{Considerações iniciais: situando a questão}

Reflexões platônicas sobre a natureza do conhecimento, sua definição como crença verdadeira acompanhada de razões, e sobre por que conhecimento é melhor do que crença verdadeira permanecem alvos do interesse filosófico, constituindo questões centrais na agenda epistemológica contemporânea. Diante disso, não é surpreendente que um dos maiores desafios no cenário epistemológico das últimas décadas tenha sido os contraexemplos a essa análise clássica, colocados por Gettier (2009), visando mostrar que as condições da análise tripartite, embora necessárias, não são suficientes para explicar casos de conhecimento. Diversas são as maneiras de se montar casos do tipo Gettier, em todas o objetivo é apresentar situações nas quais as três condições da definição clássica são satisfeitas mas não temos um caso de conhecimento. Uma delas é a seguinte: consideremos uma situação na qual o sujeito tem uma crença bem justificada mas que resulta ser verdadeira apenas por um golpe de boa sorte. Essa boa sorte neutraliza determinada circunstância que, apesar de infeliz do ponto de vista epistêmico, não altera a posse de boas razões da parte do sujeito, embora desconecte essas razões do fato relevante para a verdade da crença.

Imaginemos um caso de tipo Gettier no qual o sujeito avista, em meio ao campo, uma forma que parece distintamente ser uma ovelha e, com base nessa percepção, ele forma a crença de que há uma ovelha no campo. De fato, esta crença é verdadeira porque há uma ovelha no campo, mas ela está fora do campo de visão do sujeito, escondida atrás de uma árvore, o objeto avistado por ele é na verdade um cão disfarçado de ovelha. Este é um caso no qual o sujeito tem uma crença que é perceptualmente bem justificada (em grau suficiente para conhecimento) e verdadeira, mas não é um caso de conhecimento porque a crença é verdadeira apenas devido à intercorrência de acasos que se neutralizam. A lição que epistemólogos aprenderam com Gettier foi a de que conhecimento é incompatível com 
sorte, e enquanto houver algum grau de independência entre a justificação e a verdade da crença (como admitem as teorias epistemológicas falibilistas, que atualmente constituem a maioria), as três condições - crença, verdade e justificação - não serão suficientes para explicar conhecimento por permitirem a intercorrência de casualidade.

Alguns epistemólogos têm buscado estratégias teóricas visando emendar a definição de conhecimento, procurando colocar condições que a imunizem a contraexemplos de tipo Gettier. Em tempos de falibilismo, o esforço tem se concentrado no oferecimento de uma explicação de conhecimento na qual o sujeito $S$ só sabe a proposição $p$ se não é acidental que ele tenha uma crença verdadeira. É neste cenário que Ernest Sosa (1980) propõe analisar conhecimento a partir de propriedades do sujeito enquanto agente epistêmico, de modo que a avaliação epistêmica positiva do agente explicaria a avaliação epistêmica positiva da crença, invertendo assim a direção tradicional de análise, na qual a qualificação epistêmica do sujeito deriva da avaliação positiva da crença. Desse modo, as propriedades do agente assumem valor epistêmico básico, a partir do qual as crenças desse agente podem adquirir justificação e, se verdadeiras, ser casos de conhecimento.

Inspiradas pela proposta de Sosa, várias teorias na epistemologia recente procuram explicar conhecimento em termos de obtenção de crença verdadeira devida ao caráter virtuoso do agente. Essas propostas têm em comum a alegação de que, quando a crença verdadeira é obtida via ato virtuoso do agente, ela é crédito desse agente porque o sucesso cognitivo é atribuído (pelo menos parcialmente) à sua capacidade cognitiva, sendo que nessas circunstâncias a obtenção de crença verdadeira não pode ter sido acidental. Desse modo, colocar como condição necessária que o sucesso cognitivo seja devido ao caráter do agente permite estabelecer com clareza a diferença entre casos de conhecimento e casos de tipo Gettier, nos quais o agente fracassa em obter conhecimento porque alcançou crença verdadeira de modo acidental, uma vez que são fatores fortuitos, alheios à sua agência epistêmica, que explicam (pelo menos em parte) a aquisição de crença verdadeira.

\section{Involuntarismo doxástico e agência epistêmica}

Ainda que a noção de agência epistêmica seja central para teóricos da virtude, e que a expressão agente epistêmico seja com frequência usada na literatura epistemológica, existe um grande debate acerca de sua legitimidade. Agentes praticam ações, logo um agente epistêmico seria aquele que pratica ações epistêmicas, isto é, ações de algum modo relacionadas ao conhecimento proposicional. Por conseguinte, ações epistêmicas devem estar, de algum modo, conectadas a razões para aceitar uma dada proposição $p$ como sendo verdadeira, isto é, razões para crer que 
p. Assim, cabe perguntar: Quais ações poderiam ser consideradas epistêmicas? Haveria um ato de crer? Ações epistêmicas poderiam resultar de razões não epistêmicas? Ainda que quotidianamente seres humanos pratiquem, em suas vidas cognitivas, atividades de natureza investigativa constituídas pela coleta e avaliação de evidências, esta prática não pode ser confundida com a atitude assumida pelo sujeito $S$ quando, de modo inteiramente involuntário, diante de determinado conjunto de evidências em favor de determinada proposição, $p, S$ crê que $p$. Da mesma maneira, não podemos confundir as razões que $S$ eventualmente pode ter para buscar mais evidências quanto à verdade de $p$, que podem incluir razões não epistêmicas (razões de outra natureza, tais como pragmáticas, prudenciais, morais), com as razões que, em dado momento $t, S$ tem para crer que $p$, que são exclusivamente epistêmicas, isto é, estão relacionadas apenas à eventual verdade de $p$.

Por outro lado, a ideia de agência tem relação estreita com a ideia de responsabilidade, a qual por sua vez, em ética ou em epistemologia, pressupõe algumas condições tais como liberdade e controle por parte do agente. Da perspectiva epistêmica, o partido majoritário entende que um agente só pode ser responsável por sua crença caso ele possa ter algum controle sobre ela, e seja livre para decidir crer ou não crer. Essa mesma maioria nega que possamos ter tal controle, visto que crenças são estados mentais involuntários, que seres racionais formam de modo automático diante das evidências disponíveis. Quando consideramos uma proposição e ela nos parece verdadeira, não temos como resistir à atitude de afirmar esta proposição, isto é, crer nela, da mesma maneira que é irrefreável nossa reação de recusa a crer em uma proposição para a qual temos evidências em contrário.

A crítica à posição conhecida como deontologismo epistêmico ${ }^{2}$ se insurge contra a proposta de que crenças possam ser avaliadas epistemicamente em termos de responsabilidade e cumprimento de deveres e obrigações epistêmicas, alegando que a tese de que somos livres para crer, isto é, de que nossas crenças estão sujeitas a nosso controle voluntário, é implausível. Se dever implica poder, argumentam eles, o sujeito só pode ser censurado ou elogiado na medida em que poderia ter feito de modo diferente e escolheu fazer daquele modo. Por conseguinte, se a ideia de ser responsável, inclusive quanto a crer, pressupõe que o sujeito tenha livre escolha. Se crenças são estados mentais involuntários,que simplesmente nos acontecem, então não somos livres para decidir crer ou não crer em determinada proposição, e consequentemente não podemos ser responsáveis epistemicamente (e o deontologismo epistêmico é falso).

\footnotetext{
${ }^{2}$ Embora haja algumas variações entre as abordagens deontológicas em epistemologia, todas têm em comum o entendimento de que crenças podem ser epistemicamente avaliadas em termos deontológicos tais como "dever", "permissibilidade", "responsabilidade", "mérito", "não censurabilidade".
} 
$\mathrm{O}$ argumento do determinismo epistêmico contra a possibilidade de responsabilidade (e por via de consequência, de agência) pode ser formulado como segue:

1. Se o domínio epistêmico é determinado (involuntarismo doxástico), então ninguém pode agir epistemicamente de modo diferente daquele que agiu de fato;

2. Para toda ação $\Phi$ e sujeito $S$, se $S$ é epistemicamente responsável por fazer $\Phi$ então ele poderia ter se abstido de fazer $\Phi$;

3. O domínio epistêmico é determinado;

4. Ninguém pode ser responsável epistemicamente.

H. Frankfurt (1969) propôs contraexemplos que atacam a versão eticista da premissa 2 do argumento acima, isto é, a tese de que só pode haver atribuições de responsabilidade se houver a possibilidade de ter agido de forma diferente. ${ }^{3}$ No campo da ética essa premissa é conhecida como Princípio das Possibilidades Alternativas (PPA), ${ }^{4}$ negado por alguns teóricos sob a alegação de que a responsabilidade de um agente não pode depender de circunstâncias contrafactuais (condições modais), mas apenas do que o agente faz na situação em que efetivamente se encontra.

\section{Condições contrafactuais e atribuição de responsabilidade}

$\mathrm{Na}$ perspectiva epistêmica, condições contrafactuais têm tido importante papel na explicação de conhecimento, em uma ampla discussão que parece estar longe de alcançar sua conclusão. ${ }^{5}$ Não vou me ocupar aqui

\footnotetext{
${ }^{3}$ A estrutura dos casos propostos por Frankfurt segue o seguinte modelo: João delibera sobre a ação de levantar seu braço e decide levantá-lo, passando à ação de levantar o braço com base em sua decisão. No entanto, sem que João saiba, um neurocientista está em condições de afetar seu cérebro de modo que, caso João tivesse dado sinais de que não levantaria espontaneamente seu braço, o neurocientista teria causado sua decisão de levantar o braço. Assim, João é o agente da ação de levantar o braço quando ele é a causa de seu braço levantar porque decide fazê-lo com base em sua decisão de levantar o braço. Caso o neurocientista, ao manipular seu cérebro, faça com que ele decida levantar o braço, João não seria mais o agente de sua ação, porque a causa de sua ação seria um manipulador externo. A questão colocada por Frankfurt diz respeito à relevância da situação contrafactual quando é o caso que João levanta seu braço porque decide assim fazer, i.e., qual seria a importância (se alguma) para a atribuição de responsabilidade do fato de que João não poderia ter refreado sua ação dado que, nesse caso, o manipulador externo entraria em ação e causaria o levantar de seu braço.

${ }^{4}$ Em inglês "Principle of Alternate Possibilities (PAP)".

${ }^{5}$ Alguns teóricos responderam aos contraexemplos de Gettier propondo análises de conhecimento requerendo como condição necessária que o sujeito esteja em alguma dada relação modal em relação à proposição conhecida. Inicialmente, Nozick (1981) formulou a seguinte análise de conhecimento: o sujeito $S$ sabe a proposição $p$ se e somente se (i) $S$ crê que $p$; (ii) $p$ é verdadeira; (iii) $S$ não creria que $p$ se $p$ fosse falsa; e (iv) $S$ creria que $p$ se $p$ fosse verdadeira. Em outras palavras, para que $S$ saiba que $p$ é necessário que ele seja sensível à verdade (ou falsidade) de $p$ em mundos possíveis próximos. Diante das objeções
} 
especificamente do debate sobre condições modais para o conhecimento, meu interesse presente se restringe à importância de se considerar situações contrafactuais para a atribuição de responsabilidade, em análogos epistêmicos de casos do tipo Frankfurt, tentando extrair desse exercício consequências epistemicamente interessantes para explicações de conhecimento em termos de crédito epistêmico. Em linhas gerais, a tese de Zagzebski (2001) é a de que casos epistêmicos do tipo Frankfurt poderiam servir para mostrar que podemos ser responsáveis epistemicamente mesmo quando não poderíamos ter agido de outra maneira, isto é, quando não poderíamos ter tido um estado doxástico diferente daquele que tivemos, com respeito a determinada proposição em determinado momento. Se essa argumentação estiver correta, então ela viria em apoio da alegação de que pode haver responsabilidade epistêmica mesmo se crenças são involuntárias, e de que a agência é condição necessária para que o sujeito tenha crédito pela obtenção de crença verdadeira e, consequentemente, para que ele alcance conhecimento.

O caso Frankfurt epistêmico oferecido por Zagzebski é o seguinte:

Suponha que Jones é muito boa em identificar safras de [vinho] Bordeaux. Em particular, ela não tem dificuldade em distinguir um Château Margaux safra 94 de outros vinhos muito similares. Black sabe que Jones irá degustar diferentes safras de Margaux, [e] que ela não saberá antecipadamente qual o ano da safra que irá degustar. Ele instalou um dispositivo dentro da cabeça de Jones que pode fazê-la crer que o vinho seguinte a ser degustado é um Margaux 94, quer ele seja ou não [um Margaux 94]. (Não interessa por que Black quer fazer isso.) Quando Jones provar o próximo vinho, se ela for julgar que se trata de um Margaux 94 o dispositivo não fará nada. Mas se Jones for julgar que se trata de outro vinho, o dispositivo irá interferir em suas sensações gustativas levando-a a pensar que se trata de um Margaux 94. Suponha, então, que ela prove um [Margaux] 94 e creia que é um [Margaux ] 94, e que o dispositivo de Black não faça nada além de monitorar o que está ocorrendo no sistema nervoso de Jones. [Nesse caso] As faculdades de Jones, sua memória e seu paladar, estão funcionando bem e ela obtém uma crença verdadeira da maneira normal. (ZAGZEBSKI, 2001, p. 148)

colocadas contra a condição de sensibilidade, que caracteriza a teoria do rastreamento, Sosa procurou enfrentar as dificuldades levantadas pelos casos Gettier oferecendo uma explicação de conhecimento que inclui uma condição contrafactual requerendo segurança: se o sujeito $S$ sabe a proposição $p$, então $S$ não creria facilmente que $p$ se $p$ não fosse o caso. Essa análise também foi alvo de contraexemplos, que levaram Sosa a revisar sua posição substituindo a condição modal por uma condição de competência, definindo competência em termos de segurança. Essa manobra teórica terá consequências interessantes que serão objeto de nossa atenção na sequência desse texto. 
É importante ressaltar que, na situação sugerida por Zagzebski, Black é um interventor externo que pode manipular os processos cognitivos de Jones, de maneira que suas condições internas, aquelas da pele para dentro, são as únicas afetadas, pois o dispositivo é colocado de modo a interferir apenas na capacidade de Jones de reconhecer as características do vinho degustado, sem alterar seus inputs sensoriais. O objetivo teórico de Zagzebski ao conceber a situação de Jones nestes termos é precisamente lançar luz sobre a relevância que a agência epistêmica tem na avaliação de crenças, procurando mostrar que a manipulação ao nível das condições internas do agente pode ter alto impacto em sua vida epistêmica precisamente pela anulação de sua agência, impedindo a atribuição de responsabilidade epistêmica e consequentemente, de crédito pelo sucesso cognitivo. Vale ainda observar que a intervenção característica de casos do tipo Frankfurt é essencialmente diferente daquela proposta em situações, como a hipótese do gênio maligno ou do cérebro em uma cuba, que envolvem a manipulação de algo externo ao sujeito intervindo nos itens que são recebidos por seu sistema sensorial, de maneira que ele é sistematicamente enganado e levado a erro, mas sem que aspectos de seu caráter cognitivo, tais como suas capacidades de raciocínio ou perceptual, sejam afetadas. ${ }^{6}$

Conforme Zagzebski (2001, p. 149), por definição, um agente precisa "exercer uma capacidade e, pelo menos tipicamente, produzir certo tipo de efeito por meio do exercício desta capacidade", ou seja, um agente efetivo é aquele que atinge a finalidade por ele buscada em decorrência do exercício de sua capacidade. No caso epistêmico, quando a motivação do agente é crer em verdades, ele recebe crédito por alcançar seu objetivo quando a obtenção de crença verdadeira é devida, ainda que não exclusivamente, à sua agência. Nessa perspectiva, mesmo que crenças sejam involuntárias, a agência do sujeito, isto é, a manifestação de seu caráter intelectual virtuoso, pode e deve ser importante enquanto fator causal para a obtenção de crença verdadeira. Quando os processos causais envolvidos na formação da crença prescindem dessa agência, o sujeito perde tanto o crédito pela crença verdadeira, quanto o conhecimento. A conclusão de Zagzebski é a de que "A satisfação de contrafactuais apropriados não é

\footnotetext{
${ }^{6}$ Embora reconheça o impacto que a consideração de casos Frankfurt epistêmicos têm na teoria de Sosa, que o levaram a reconsiderar o papel da condição de segurança, Comesaña (2013) critica a formulação do caso Frankfurt epistêmico nos termos propostos por Zagzebski, entendendo que a intervenção deveria ocorrer ao nível das evidências, ou dos dados sensoriais, que o sistema cognitivo de Jones recebe. Contudo, Comesaña parece não entender o ponto visado por Zagzebski, que se coloca precisamente no aspecto que é relevante epistemicamente por mostrar a importância da agência epistêmica do sujeito enquanto condição para a aquisição de conhecimento. É precisamente com base nisso que Zagzebski conclui que situações do tipo Gettier se caracterizam pela ausência de agência epistêmica, oferecendo uma explicação satisfatória de por que não há conhecimento nesses casos.
} 
constitutiva da agência, mas um sinal dela [...] [sinal] de que o ato/crença pertence realmente ao agente, de que ele recebe crédito por ele" (ZAGZEBSKI, 2001, p. 149). Assim, ser agente é central na explicação da obtenção de conhecimento, pois ela garante que a acidentalidade exemplificada nos casos Gettier é evitada dado que a aquisição de crença verdadeira é atribuível ao caráter cognitivo do agente (i.e., é crédito seu), ele é o responsável pelo sucesso em alcançar o fim epistêmico buscado por ele.

\section{Sosa sobre agência epistêmica: as notícias recentes}

A última posição assumida por Ernest Sosa em sua teoria da virtude epistêmica está em grande consonância (ou pelo menos assim considero) com a concepção de Zagzebski apresentada na seção anterior, constituindo um aporte de força argumentativa para teorias do crédito em epistemologia. Em sua última publicação, Sosa (2015, p. 36) propõe uma visão "ecumênica" em epistemologia da virtude, contemplando ambas as intuições com respeito ao caráter das virtudes, a confiabilista e a responsabilista, colocando a noção de agência em posição central para o tratamento de questões epistemológicas. Esse movimento convergente pode ser considerado uma sequência natural de sua defesa da ideia de que ter crédito pela crença verdadeira é condição necessária para a avaliação epistêmica positiva da atitude doxástica e, por consequência, para a obtenção de conhecimento. Esse entendimento não é novo em sua teoria, ele está presente em vários momentos de sua obra, como por exemplo, quando diz que a epistemologia da virtude é "a concepção de que o conhecimento é crença cujo sucesso é 'creditável' ao sujeito que crê" (SOSA, 2011, p. 86), e que conhecimento é um estado diferente daquele de mera crença verdadeira porque nele o sucesso cognitivo (alcançar crença verdadeira) é atribuível à performance virtuosa do agente e, portanto, creditável a ele (SOSA, 2003, p. 167). A teoria defendida por Sosa parece, assim, ter se colocado paulatinamente, e hoje mais do que nunca, em posição de reconhecer a indispensabilidade de se conceber a avaliação epistêmica em termos que incluem a dimensão subjetiva e a agência do sujeito:

\footnotetext{
Uma epistemologia verdadeira atribuiria a tal virtude intelectual responsabilista-cum-confiabilista o papel principal ao considerar questões centrais na tradição. [...] é assim devido ao tipo de conhecimento que está no centro da epistemologia tradicional, do pirronismo a Descartes. [...] Este é um conhecimento que requer o endosso livre e volitivo do sujeito que julga, ou no mínimo a disposição correspondente a tal endosso. (SOSA, 2015, p. 2-3)
}

Conforme Sosa (2015, cap. 9), seres humanos são agentes porque podem performar ações de duas maneiras: enquanto funções e enquanto esforços. A esfera das performances se caracteriza por ser ativa, se 
contrapondo à passividade característica da esfera onde se situam o que Sosa chama de "sofrimentos", estados nos quais o sujeito não pode interferir por meio de sua vontade, mas que lhe ocorrem automática e involuntariamente. Esse contraste leva naturalmente à divisão entre conhecimento animal, constituído por crenças que são "estados armazenados que guiam [nossa] conduta subconscientemente", e que caracterizam o domínio onde somos passivos; e conhecimento reflexivo, constituído por crenças judicativas, que "são uma disposição para julgar afirmativamente em resposta a uma questão no esforço de responder corretamente, alcançando a verdade, ou sendo suficientemente confiável ou até mesmo apto [por alcançar a verdade por meio de sua habilidade]", sendo que essa esfera reflexiva estaria sob nosso "controle livre" (SOSA, 2015, p. 209).

A divisão proposta por Sosa, entre esfera ativa e esfera passiva, oferece vantagens teóricas importantes para a viabilidade da ideia de agência e responsabilidade epistêmicas nos termos defendidos em propostas como a de Zagzebski e Greco, ${ }^{7}$ ao proporcionar clareza quanto às condições nas quais o agir epistêmico seria plausível, i.e., quando o sujeito não é passivo e tem algum grau de liberdade que lhe dá espaço para escolha e decisão, permitindo-lhe a formulação de juízos. Sosa (2015, p. 193 e seguintes) insiste em que, entre os dois extremos, há uma "região intermediária, entre passividade e ação livre, na qual performances podem ser determinadas racionalmente mesmo quando não são livremente determinadas. [...] há [...] um quadro deôntico-funcional mais amplo que não contém esforços livremente determinados".

Essas funções, ainda que não sejam livremente determinadas, podem ser avaliadas positiva ou negativamente (mesmo que não engendrem elogio ou censura) devido à sua motivação - funções racionais têm, tipicamente, motivações racionais na forma de razões pelas quais o agente funciona como o faz, e Sosa propõe que o fundamento racional estaria nesse domínio. Desse modo, é plausível afirmar que essas funções podem ser racionalmente determinadas mesmo que não sejam livremente determinadas. Consideremos nossa atitude de assentimento (crença) diante de uma proposição que se apresenta a nós como verdadeira. Nos termos de Sosa, quando cremos em proposições que nos parecem verdadeiras somos agentes por funcionarmos adequadamente, ainda que não sejamos livres: "Funcionamos de modo adequado precisamente por estarmos passivamente atraídos na medida correta [...]” (2015, p. 195). Esse tipo de ação por função, orientada para a verdade, estaria sujeito à avaliação e seria relevante para a qualificação epistêmica. No âmbito dos esforços, a agência se revela por meio do "ato de juízo", ao nível do que Sosa refere como

\footnotetext{
${ }^{7}$ Embora não haja espaço aqui para defender esse ponto, considero adequado incluir o confiabilismo de agente, defendido por John Greco (1999, 2003), entre as teorias que podem se beneficiar dessa abordagem.
} 
"conhecimento judicativo" (SOSA, 2015, p. 25). Juízos são afirmações que resultam do esforço realizado pelo agente na intenção de crer em verdades, ou, na terminologia de Sosa, de "crer aptamente" (SOSA, 2015, p. 67).

E esse "juízo" que o sujeito está disposto a conceder é um ato consciente distintivo, ou um estado conscientemente sustentado. É este ato ou estado que está dentro de nosso controle livre quase tão frequentemente e tão plausivelmente quanto estão as escolhas que fazemos ordinariamente e as intenções conscientes que sustentamos. (SOSA, 2015, p. 209)

\section{Considerações finais}

As situações contrafactuais apresentadas em casos Frankfurt mostram que considerar possibilidades alternativas é relevante para distinguir os casos onde há agência. Conforme a argumentação de Zagzebski, a satisfação de condições contrafactuais é importante para estabelecer quando o sujeito é agente, e ser agente é condição necessária para a atribuição de responsabilidade e crédito pela crença verdadeira. Por conseguinte, o exercício da agência e o crédito pela crença verdadeira que ele acarreta é condição necessária para que o sujeito alcance conhecimento.

No caso concebido por Zagzebski, Jones, a especialista em vinhos, recebe crédito por sua crença por motivos análogos aos que levam à responsabilização moral de agentes em casos Frankfurt - Jones sabe que se trata de um Margaux 94, ainda que ela não satisfaça o teste das possibilidades alternativas, ou a condição de sensibilidade, uma vez que ela não rastrearia a verdade no mundo próximo no qual haveria a interferência do dispositivo, fazendo com que ela formasse a mesma crença, de que o vinho é um Margaux 94, o que nesse caso seria falso. O ponto relevante a ser ressaltado está nas consequências epistêmicas quando há manipulação do caráter cognitivo do agente: em casos epistêmicos clássicos do tipo Frankfurt, o sujeito manteria seu caráter cognitivo virtuoso e confiável, ${ }^{8}$ porque a manipulação seria apenas uma possibilidade contrafactual, que não se efetiva e é apenas ocasional (ocorreria uma única vez). Se a manipulação fosse sistemática e intermitente ao longo da vida do agente, sendo algumas vezes efetiva e outras apenas uma possibilidade, então teríamos a eliminação da agência do sujeito, e a obtenção de crença verdadeira não poderia mais ser atribuída ao seu caráter cognitivo, impedindo-o de alcançar conhecimento. Assim considerando, parece adequado o entendimento de

\footnotetext{
${ }^{8}$ A meu ver, contra Comesaña, Zagzebski concebe o caso de manipulação colocando em foco o aspecto adequado para a avaliação epistêmica ao considerar como alvo da intervenção o controle de aspectos do caráter cognitivo do agente, configurando assim situações de coerção. Já nos casos onde a intervenção é do tipo dos exemplos envolvendo gênios malignos e neurocientistas loucos, são os dados recebidos pelos sentidos dos agentes que são manipulados e não a natureza cognitiva do agente.
} 
Zagzebski de que a condição contrafactual seria importante enquanto sinalizadora da presença da propriedade de ser agente, condição necessária para o conhecimento.

Além disso, parece plausível supor que a intuição motivadora de Sosa ao conceber a condição de segurança como incorporada à noção de competência tenha origem na consideração de situações do tipo Frankfurt, ${ }^{9}$ de modo que é cabível afirmar que Zagzebski (2001) coloca condições para o conhecimento em termos que Sosa hoje parece aceitar: agência epistêmica é condição necessária para o conhecimento, pois, na medida em que Jones é reflexiva e capaz de endossar ou rejeitar as crenças produzidas por interferência do dispositivo, ela não está sendo manipulada, mantendo sua agência e, intuitivamente, alcançando conhecimento. Contudo, caso a intervenção tenha algum impacto em sua capacidade reflexiva, "então Jones provavelmente terá de fato perdido sua agência" (ZAGZEBSKI, 2001, p. 152-153), e com isso não poderá adquirir conhecimento. Incluir a condição da agência permite explicar por que não temos conhecimento nos casos em que crenças verdadeiras são obtidas de modo fortuito - nessas situações o agente não tem conhecimento porque ele não tem crédito epistêmico devido à ausência de agência na obtenção de crença verdadeira. A recente harmonia entre a linha argumentativa de Zagzebski e Sosa constitui uma promissora direção para a defesa da plausibilidade e relevância teórica da noção de agência epistêmica e, por extensão, para as explicações de conhecimento em termos de crédito epistêmico defendidas por alguns teóricos da virtude. ${ }^{10}$

\section{Referências bibliográficas}

COMESAÑA, J. Safety and Epistemic Frankfurt Cases. In: TURRI, J. (ed.), Virtuous Thoughts: The Philosophy of Ernest Sosa. Springer, 2013. P. 165178.

FRANKFURT, H. Alternate Possibilities and Moral Responsibilities. The Journal of Philosophy, v. 66, p. 829-839, 1969.

GETTIER, Edmund. Is Justified Belief Knowledge? In: SOSA, E.; KIM, J.; FANTL, J.; MCGRATH, M. (eds.). Epistemology: an anthology. Malden: Blackwell Publishing, 2009. p. 192-193. (Reimpressão da "Analysis", v. 23, p 121-123, 1963)

GRECO, J. Agent Reliabilism. Noûs, v. 33, (Philosophical Perspectives, n.13), p. 273-296, 1999.

\footnotetext{
9 Em SOSA (2010), competência é definida como a "capacidade de performar bem". Nesses termos, ser competente pressupõe a cláusula de segurança, pois, por definição o agente competente é aquele que dificilmente erra. Assim, quando o sucesso do agente (em alcançar crença verdadeira) manifesta sua competência, sua performance é apta, e ele tem conhecimento porque obteve crença verdadeira pelo exercício de sua(s) competência(s), isto é, sua agência epistêmica.

${ }^{10}$ Ver GRECO (2003) e PRITCHARD (2012).
} 
Knowledge as credit for true belief. In: DEPAUL, M.; ZAGZEBSKI, L. (eds.). Intellectual virtue: Perspectives from ethics and epistemology. Oxford: Oxford University Press, 2003. p. 111-134.

NOZICK, R. Philosophical Explanations. Cambridge: Harvard University Press, $1981.764 \mathrm{p}$.

PRITCHARD, D. Anti-Luck Virtue Epistemology. In: The Journal of Philosophy, v. 109, n. 3, p. 247-279, 2012.

SOSA, E. The Place of Truth in Epistemology. In: DEPAUL, M.; ZAGZEBSKI, L. (eds.) Intellectual Virtue: Perspectives from Ethics and Epistemology. Oxford: OUP, 2003. p. 155-179.

. How Competence matters in Epistemology. Philosophical Perspectives, v. 24, Epistemology, p. 465-475, 2010.

Reflective knowledge: Apt belief and reflective knowledge. Oxford: Oxford University Press, 2011. 163 p. Judgement and Agency. Oxford: Oxford University Press, 2015. $224 \mathrm{p}$.

ZAGZEBSKI, L. Must knowers be agents? In: FAIRWEATHER, A.; ZAGZEBSKI, L. (Eds.). Virtue Epistemology: essays in Epistemic Virtue and Responsibility. N. York: OUP, 2001. p. 142-157. 